\title{
HYDRO-GEOPHYSICAL SURVEY OF GROUNDWATER DEVELOPMENT IN OKHA COMMUNITY (ALONG SAPELE ROAD), IKPOBA OKHA L.G.A. EDO STATE
}

\author{
M. 0. Ehigiator* \\ DEPT. OF BASIC SCIENCES (GEOPHYSICS OPTION) BENSON IDAHOSA UNIVERSITY, BENIN CiTy, EDO STATE, NIGERIA \\ Email address: mehigiator@biu.edu.ng
}

\begin{abstract}
This Research is based on geophysical survey of the ground water development of Okha community along Sapele Road in Benin City. The Schlumberger configuration was used for a total spread (L) of $400 \mathrm{~m}$. The location

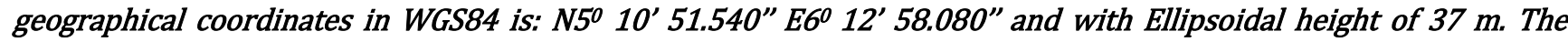
results indicate that seven sub layers were identified as reflected from the table. The result of data processing by the software package was integrated in order to arrive at the realistic composition and layering of the subsurface. The interpretation suggested that the area was underlain with substantive aquiferous formation but at a depth not exceeding 93.4 metres (306.43 ft). However, adequate borehole logging of the samples from well bore to enable the proper screening of the aquifer zones which are captured is recommended,
\end{abstract}

Keywords: WGS84, Aquifer, formation, depth, logging, borehole.

\section{INTRODUCTION}

The aim of any resistivity survey is to delineate Vertical and Horizontal boundaries with electrical contrast [1] This Hydro-geophysical Survey was conducted for the purpose of surveying and studying the proposed water borehole site in Okha, Ikpoba Okha LGA of Edo State, using the Vertical Electrical Sounding (VES) technique. The survey is expected to investigate the subsurface complexity of the sites in respect of lithology and to recommend the total drill depth based on the prospective aquifer unit so identified. The subsurface of this area consists of sand and clay units with intercalations of shale and Mudstone. The area is predominantly sedimentary terrain belonging to the Benin Formation.

Global Navigation Satellite System (GNSS) is one of the most recent essential tools that have revolutionized almost all applications that require very high-accurate positioning, navigation and timing as well in frequency domain [2]. This development has now seen the implementation of high accurate stations positioned around the world. Technological improvements in GNSS receivers have made GNSS surveying to achieve millimeter -level accuracy positioning in static model [3]. For the purpose of location determination, a handheld Garmin X10 GNSS receiver with accuracy ranging between $3 \mathrm{~m}$ to $5 \mathrm{~m}$ was used. The value so obtained is in World Geodetic System (WGS84) presented in Latitude, Longitude and Ellipsoidal height. The value so obtained need to be transformed for WGS84 to Nigeria Minna datum. Positioning with GNSS can now be performed by either point positioning or differential (relative) Positioning [4, 5]. GNSS point positioning employs one GNSS receiver, while differential positioning employs two (or more) GNSS receivers simultaneously tracking the same satellites $[6,7]$.

\section{METHODOLOGY}

To compliment surface geological mapping, Petrozenith PZ-02 Terametter Electrical Resistivity Equipment was used to conduct a Vertical Electrical Sounding (VES). The Schlumberger configuration was used for a total spread (L) of $400 \mathrm{~m}$. A VES station was located in front of the proposed water borehole site. $200 \mathrm{~m}(\mathrm{~L} / 2)$ was covered on the right running towards Benin City, and another $200 \mathrm{~m} \mathrm{(L/2)}$ was run on the left towards Ologbo. Necessary precautions required in geo-electric measurement were duly considered and maintained. The survey lasted between $10.15 \mathrm{hr}$ to $12.20 \mathrm{hr}$ under favourable weather condition. 


\subsection{Datum Transformation}

The term Datum is used to describe the reference frame for geodetic computation [8] which defines the parameters regarding the relationship between the ellipsoid and the real earth (Geoid). The position of a point on the earth surface can be given either in terms of $(\varphi, \Lambda, h)$ or $(X, Y, Z)$ coordinates systems which every system is used has an origin and have a relationship for transformation to other systems. The transformation from $(\varphi, \Lambda, h)$ system to $(\mathrm{X}, \mathrm{Y}, \mathrm{Z})$ system can be achieved using the following relationship $[9,10]$.

The formula to perform the Molodensky Abridge Model for transforming WGS84 to the equivalent Minna datum Geographical coordinates read thus:

$$
\begin{gathered}
\begin{array}{c}
\Delta \varphi^{\prime \prime}=\left[-t_{x} \operatorname{Sin} \varphi \operatorname{Cos} \lambda-t_{y} \operatorname{Sin} \varphi \operatorname{Cos} \lambda+t_{z} \operatorname{Cos} \varphi\right. \\
\left.+(a \Delta f+f \Delta a) \operatorname{Sin} 2 \varphi /\left(M \operatorname{Sin} 1^{\prime \prime}\right)\right] \\
\Delta \lambda^{\prime \prime}=\left[-t_{x} \operatorname{Sin} \varphi \operatorname{Cos} \lambda+t_{y} \operatorname{Cos} \lambda\right] \\
/\left(V \operatorname{Cos} \varphi \operatorname{Sin} 1^{\prime \prime}\right] \\
{ }^{o} \Delta \varphi^{\prime \prime}=\left[-t_{x} \operatorname{Sin} \varphi \operatorname{Cos} \lambda-t_{y} \operatorname{Sin} \varphi \lambda+t_{z} \operatorname{Cos} \varphi\right. \\
\left.+(a \Delta f+f \Delta a) \operatorname{Sin} 2 \varphi /\left(M \operatorname{Sin} 1^{\prime \prime}\right)\right]
\end{array} \\
V_{(\varphi)}=\frac{a_{L}}{\left(1-e^{2} \operatorname{Sin}^{2} \varphi\right)^{\frac{1}{2}} ; M_{(\varphi)}=\frac{a_{L}\left(1-e^{2}\right)}{\left(1-e^{2} \operatorname{Sin}^{2} \varphi\right)^{\frac{3}{2}}}}
\end{gathered}
$$

Where: $t x, t y, t z$ : are the translations between both datums (in geocentric coordinates);

$\varphi, \lambda, \mathrm{h}$ : geodetic co-ordinates of the local geodetic system ellipsoid;

$\Delta \varphi, \Delta \lambda, \Delta \mathrm{h}$ : corrections to transform local datum coordinates to WGS84 $\varphi, \lambda$, h;

$\Delta \mathrm{X}, \Delta \mathrm{Y}, \Delta \mathrm{Z}$ : corrections to transform local datum coordinates to WGS84 X, Y, Z;

$\Delta \mathrm{a}, \Delta \mathrm{f}$ : (WGS84 minus local) semi-major axis and flattening respectively;

a: semi-major axis of the local geodetic system ellipsoid;

f. flattening of the local geodetic system ellipsoid;

$\mathrm{M}_{(\varphi)}$ : radius of curvature in the meridian;

$\mathrm{V}_{(\varphi)}$ : Prime vertical radius of curvature;

The datum shift parameters derived by Shell Petroleum Development Company (SPDC) are presented thus: Datum Shift Parameters from WGS84 to Minna Datum Geographical coordinates are:

$t_{x}=$ plus 111.916; $t_{y}=$ plus 87.852; $t_{z}=$ minus 114.499

$a_{L}=6378249.145 ; f_{L}=1 / 293.465 ; \Delta f=$ minus

0.54750714

Mathematically transformation from one datum to another can be realized by relating the geographic coordinates $(\varphi, \Lambda, \mathrm{h})$ of both datum systems directly, or indirectly by relating the geocentric coordinates $(\mathrm{X}, \mathrm{Y}$, Z) of the datums $[13,14]$.
The transformation from $(\varphi, \Lambda, \mathrm{h})$ system to $(\mathrm{X}, \mathrm{Y}, \mathrm{Z})$ system can be achieved using the following relationship by

$$
\left.\begin{array}{c}
X=[N+h] \cos \emptyset \cos \lambda \\
Y=[N+h] \cos \emptyset \sin \lambda \\
Z=\left[N\left(1-e^{2}\right)+h\right] \sin \emptyset
\end{array}\right\}
$$

Where: $N$ is radius vector of the prime vertical, $h$ is the point above ellipsoid, $e$ is the eccentricity. $\mathrm{N}$ and $e$ are given by

$$
\left.N=\frac{e^{2}=2 f-f^{2}}{\left(1-e^{2} \sin ^{2} \emptyset\right)^{1 / 2}}\right\}
$$

Where, $a$ is the major axis of the earth and $f$ is the flattening of the reference ellipsoid. For WGS84, $a=$ $6,378,137 \mathrm{~m}, \mathrm{f}=1 / 298.257223563=0.003352810665$. These formulas used by the Standard for New Zealand Geodetic Datum in year 2000 can be used to convert the Cartesian coordinates $(\mathrm{X}, \mathrm{Y}, \mathrm{Z})$ to the geographic coordinates $\varphi, \Lambda$, h.as follows;

$$
\left.\begin{array}{c}
\tan \lambda=Y / X \\
\tan \emptyset=\frac{Z(1-f)+e^{2} a \sin ^{3} \mu}{(1-f)\left(p-e^{2} a \cos ^{3} \mu\right.} \\
h=p \cos \emptyset+Z \sin \emptyset-a \sqrt{1-e^{2} \sin ^{2} \varnothing}
\end{array}\right\}
$$

Where: $a$ and $f$ are obtained from the ellipsoid under consideration for the geodetic datum respectively.

$$
\left.\begin{array}{c}
p=\sqrt{X^{2}+Y^{2}} \\
r=\sqrt{p^{2}+Z^{2}} \\
\tan \mu=\frac{Z}{p}\left[(1-f)+\frac{e^{2} a}{r}\right]
\end{array}\right\}
$$

Figure 2 is the transformation of the acquired geographical coordinates in WGS84 to Minna datum. The transformed coordinates to the equivalent Cartesian (grid) coordinates system is also presented in figure 2 .

\subsection{Linearised Model}

For completeness, we summaries the linearisation procedure and the development of the least squares method specifically for the GPS positioning problem. First, we assume we can write the actual observation to be the sum of a modelled observation, plus an error term [8].

$$
\left.\begin{array}{c}
P_{\text {observed }}=P_{\text {model }}+\text { noise } \\
=P(x, y, z, \tau)+v
\end{array}\right\}
$$

The provisional parameter values is given as $\left(x_{0}, y_{0}, z_{0}\right.$, $\left.\tau_{0}\right)$, using Taylor's theorem the computed model can be expanded thus by ignore second and higher order terms as presented in equation [10]. 


$$
P(x, y, z, \tau)=\left\{\begin{array}{c}
P\left(x_{0}, y_{0}, z_{0}, \tau_{0}\right)+\left(x-x_{0}\right) \partial P / \partial x+\left(y-y_{0}\right) \partial P / \partial y+\left(z-z_{0}\right) \partial P / \partial z+\left(\tau-\tau_{0}\right) \partial P / \partial \tau \\
=P\left(x_{0}, y_{0}, z_{0}, \tau_{0}\right)+\left(x-x_{0}\right)+\left(y-y_{0}\right)+\left(z-z_{0}\right)+\left(\tau-\tau_{0}\right) \\
=P_{\text {observed }}+\partial P / \partial x \Delta x+\partial P / \partial y \Delta y+\partial P / \partial z \Delta z+\partial P / \partial \tau \Delta \tau
\end{array}\right\}
$$

The residual observation is the difference between the actual observation and the computed using the provisional parameter values [8].

$$
\begin{gathered}
\Delta P=P_{\text {observed }}-P_{\text {computed }} \\
=\frac{\partial P}{\partial x} \Delta x+\frac{\partial P}{\partial y} \Delta y+\frac{\partial P}{\partial z} \Delta z+\frac{\partial P}{\partial \tau} \Delta \tau+v
\end{gathered}
$$

The matrix form is given as:

$$
\Delta P=\left[\frac{\partial P}{\partial x} \frac{\partial P}{\partial y} \frac{\partial P}{\partial z} \frac{\partial P}{\partial \tau}\right] \times\left[\begin{array}{c}
\Delta x \\
\Delta y \\
\Delta z \\
\Delta \tau
\end{array}\right]
$$

The above equation represents one satellite, for $n$ satellite, we can develop similar equation given [8] which can be written as equation (13) as shown at the bottom of this page.

$$
b=A x+v
$$

The estimated residual is given as:

$$
v=b-A x
$$

The normal equation to the solution is given as:

$$
\hat{x}=\left(A^{T} A\right)^{-1} A^{T} b
$$

The design matrix A which is usually the partial derivatives of each observation with respect to each parameter derived from the provisional values assuming $\mathrm{n}=4$ and data $\mathrm{m}$, which can be written as [8]. We can derive the coefficients of A matrix by partial differentiation of the observation equations as in the following expression $[15,16]$;

$$
A=\left\{\begin{array}{cccc}
\frac{x_{0}-x^{1}}{\rho} & \frac{y_{0}-y^{1}}{\rho} & \frac{z_{0}-z^{1}}{\rho} & c \\
\frac{x_{0}-x^{2}}{\rho} & \frac{y_{0}-y^{2}}{\rho} & \frac{z_{0}-z^{2}}{\rho} & c \\
\frac{x_{0}-x^{3}}{\rho} & \frac{y_{0}-y^{3}}{\rho} & \frac{z_{0}-z^{3}}{\rho} & c \\
M & M & M & M \\
\frac{x_{0}-x^{m}}{\rho} & \frac{y_{0}-y^{m}}{\rho} & \frac{z_{0}-z^{m}}{\rho} & c
\end{array}\right\}
$$

The acquired geographical coordinates in WGS84 was Transformed to the equivalent Minna datum using Inca geodetic software. The transformed coordinates was further converted to Cartesian (grid) coordinates and the results presented in Figure 1 [17].

\subsection{Data Processing}

All field data have been subjected to manual computation and finally to computer processing techniques, applying the ipi2win Resistivity Sounding Interpretation software. For the VES, the Schlumberger electrode configuration was adopted. A Petrozenith PZ02 Terrameter was used to take field measurements of resistance (R) from which apparent resistivity Pa was calculated by the relation $[11,12]$ :

$$
L a=K \times R
$$

Where $\mathrm{R}=$ resistance in ohms

$$
\left(\begin{array}{c}
\Delta p_{1} \\
\Delta p^{2} \\
\Delta p^{3} \\
\vdots \\
\Delta p^{m}
\end{array}\right)=\left(\begin{array}{cccc}
\partial p^{1} / \partial x & \partial p^{1} / \partial y & \partial p^{1} / \partial z & \partial p^{1} / \partial \tau \\
\partial p^{2} / \partial x & \partial p^{2} / \partial y & \partial p^{2} / \partial z & \partial p^{2} / \partial \tau \\
\partial p^{3} / \partial x & \partial p^{3} / \partial y & \partial p^{3} / \partial z & \partial p^{3} / \partial \tau \\
\vdots p^{m} / \partial x & \partial p^{m} / \partial y & \partial p^{m} / \partial y & \partial p^{m} / \partial \tau
\end{array}\right) *\left(\begin{array}{c}
\Delta x \\
\Delta y \\
\Delta z \\
\Delta \tau
\end{array}\right)+\left(\begin{array}{c}
V_{1} \\
V_{2} \\
V_{3} \\
\vdots \\
V_{m}
\end{array}\right)
$$




$$
k=\left(\frac{A B}{2}\right)^{2}-\left(\frac{M N}{2}\right)^{2} \times \pi
$$

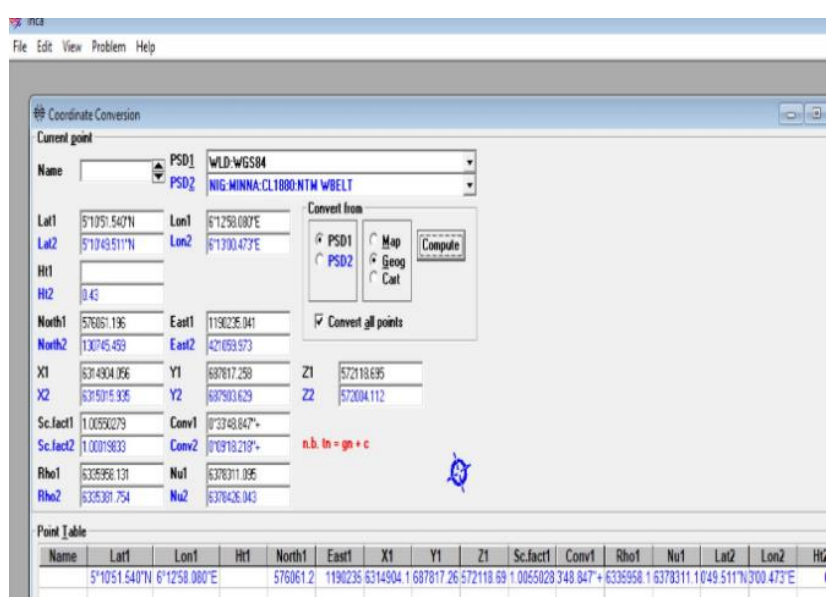

and $\mathrm{AB}$ is the current electrode spacing in meters, and $\mathrm{MN}$ is the Potential electrode spacing in meters.

$\pi=3.142$

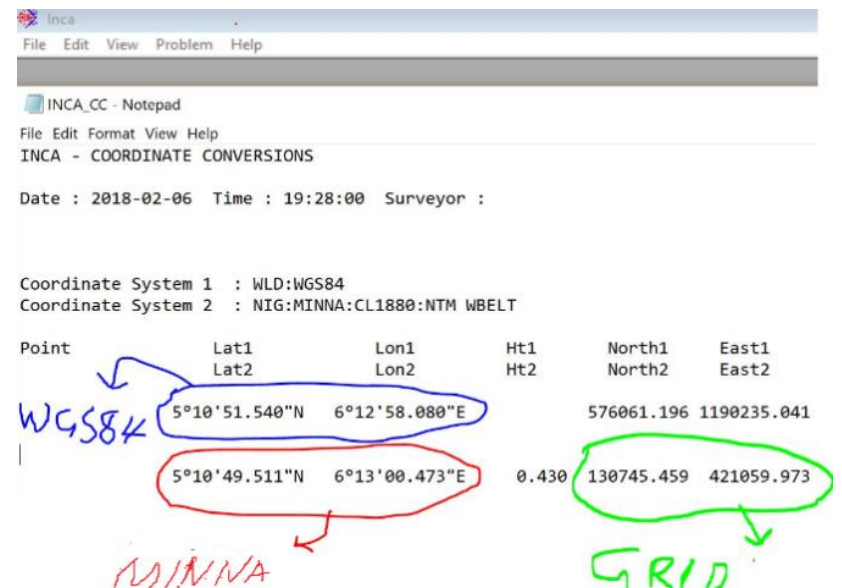

N/N/NA

Figure 1: coordinates Transformation

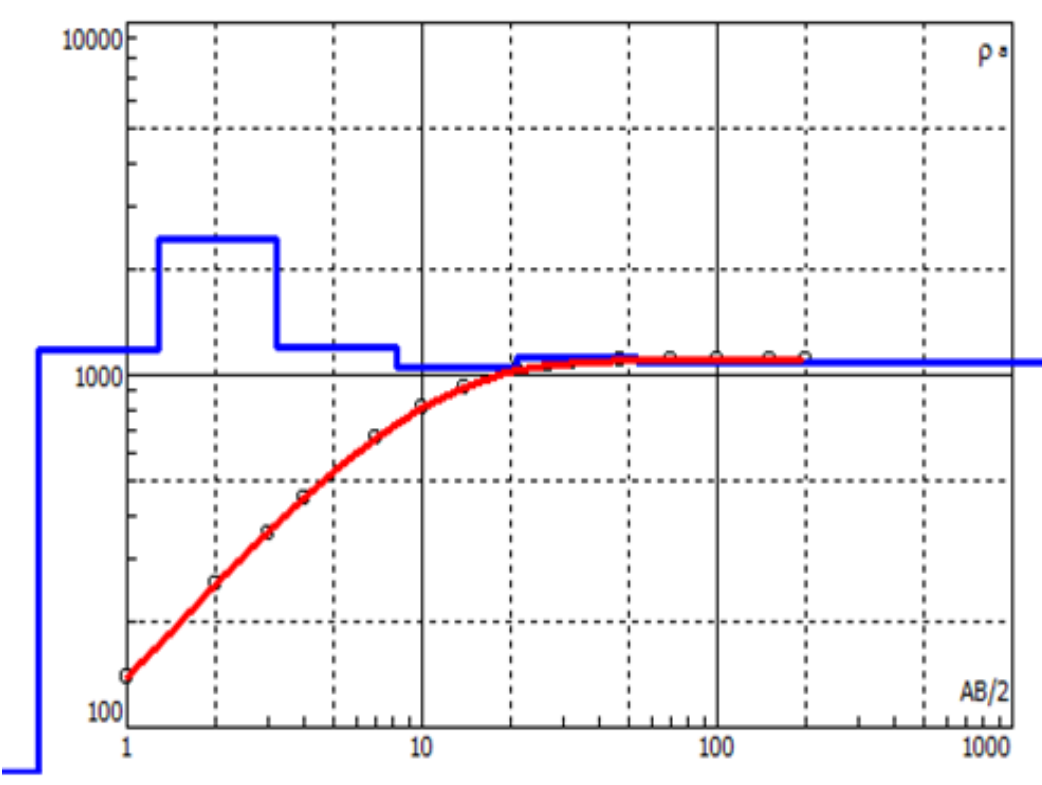

AO, m'seudo cross-section
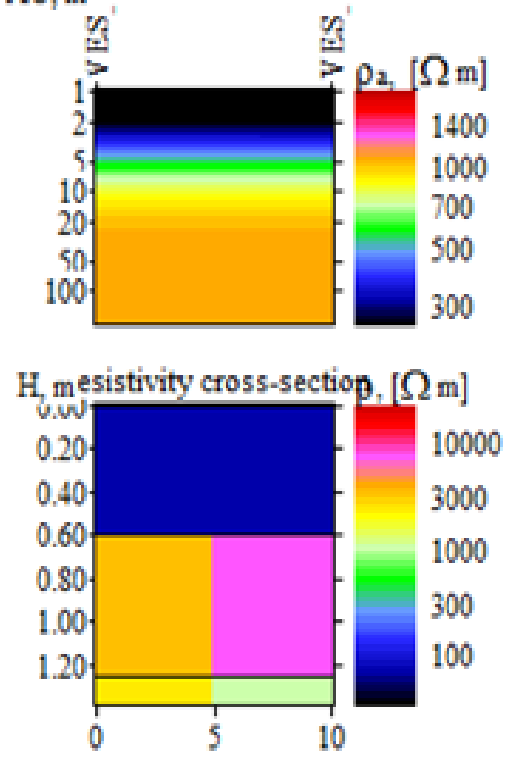

Figure 2: Layered Resistivity Model

Table 1: Resistivity Data, $S P=0, V=0$ and $I=0$

\begin{tabular}{cccc}
\hline $\mathbf{A B} / \mathbf{2}$ & $\mathbf{M N}$ & $\mathbf{K}$ & $\mathbf{R o \_ a}$ \\
\hline 1 & 1 & 2.3562 & 70.191 \\
2 & 1 & 11.781 & 334.93 \\
3 & 1 & 27.489 & 477.76 \\
4 & 1 & 49.48 & 574.96 \\
7 & 1 & 153.15 & 687.64 \\
10 & 1 & 313.37 & 676.88 \\
14 & 1 & 614.97 & 793.31 \\
21 & 1 & 1385 & 1022 \\
27 & 1 & 2289 & 1125 \\
47 & 2 & 1607 & 1015
\end{tabular}




\begin{tabular}{cccc}
\hline $\mathbf{A B} / \mathbf{2}$ & $\mathbf{M N}$ & $\mathbf{K}$ & $\mathbf{R o \_ a}$ \\
\hline 70 & 4 & 3845 & 1058 \\
100 & 10 & 3134 & 1047 \\
150 & 20 & 3519 & 1063 \\
200 & 40 & 3110 & 1289 \\
\hline
\end{tabular}

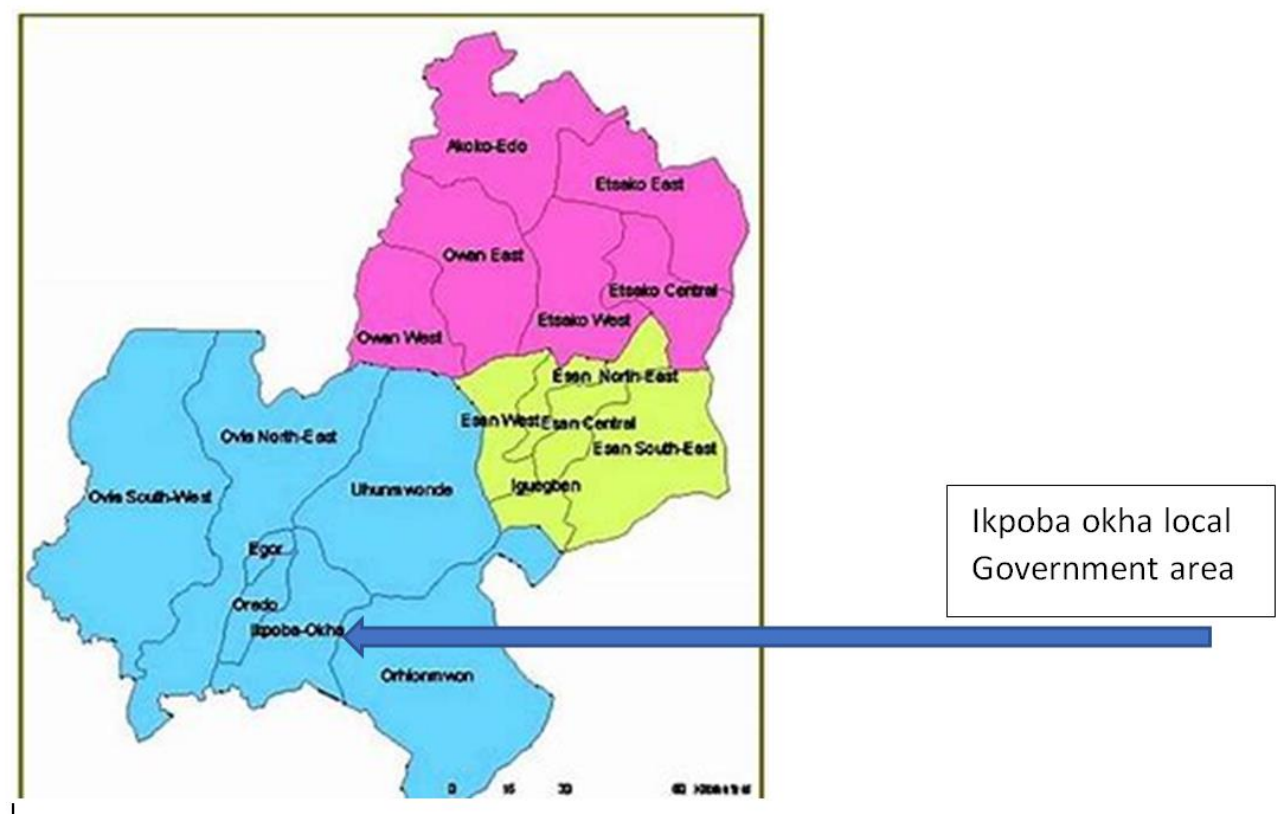

Figure 3: Map shewing Okha Community and the Geological map

Table 2: Reservoir categorization

\begin{tabular}{lllll}
\hline Layer & Depth $(\mathrm{M})$ & Thickness $(\mathrm{M})$ & Resistivity $(\Omega \mathrm{m})$ & Lithology \\
\hline 1. & 0.5 & 0.5 & 74.5 & Sandy topsoil \\
2. & 1.27 & 0.773 & 1177 & Lateritic Sub-soil \\
3. & 3.24 & 1.97 & 2443 & Sand/ Sandstone formation \\
4. & 8.25 & 5.01 & 1189 & Clayey formation \\
5. & 61 & 52.7 & 1046 & Sandy formation (prospective) \\
6. & 93.4 & 32.4 & 1120 & Clayey sand (prospective) \\
7. & Undefined & Undefined & 1086 & Sand / Sandstone \\
\hline
\end{tabular}

\section{RESULTS AND DISCUSSIONS}

Analytical result presented by the ipi2win software reveals seven sub layers as follows:

For layer 1 at a depth of $0.5 \mathrm{~m}$, the thickness was found to be $0.5 \mathrm{~m}$, Resistivity was found to be $74.5 \Omega \mathrm{m}$, while the lithology was sandy topsoil. For layer 2 at depth $1.27 \mathrm{~m}$, the thickness was found to be $0.773 \mathrm{~m}$, resistivity $1177 \Omega \mathrm{m}$ and of lithology of lateritic sub-soil. Layer 3 of depth $3.24 \mathrm{~m}$ has a thickness of $1.97 \mathrm{~m}$, resistivity of $2443 \Omega \mathrm{m}$ and lithology of sand/sandstone formation. Layer 4 of depth $8.25 \mathrm{~m}$ and thickness of $5.01 \mathrm{~m}$ has a resistivity of $1189 \Omega \mathrm{m}$ with a lithologic formation of clay. Layer 5, of depth $61 \mathrm{~m}$ and thickness of $52.7 \mathrm{~m}$ has a resistivity of $1046 \Omega \mathrm{m}$ with a sandy (prospective) lithologic formation. Layer 6, of depth of $93.4 \mathrm{~m}, 32.4 \mathrm{~m}$ and resistivity of $1120 \Omega \mathrm{m}$ has a lithologic formation of clayey (sand) prospective. Layer 7 is undefined and has an undefined thickness with a resistivity of $1086 \Omega \mathrm{m}$ and lithologic formation of clayey sand.

\section{CONCLUSIONS}

The interpretation of the results indicates that the area is underlain with substantive aquiferous formation but at a depth not exceeding $93.4 \mathrm{~m}$ (306.43 ft).

The following should be adopted for the proposed underground water development to achieve the best result: 
a. Drilling should be done to a depth not exceeding $93.4 \mathrm{~m}$ (306.43 $\mathrm{ft}$ ) to allow for large reservoirs within the aquifer units to be tapped.

b. There should be adequate borehole logging of the samples to enable the proper screening of the aquifer zones which are captured, this should be done by an experienced and registered hydrogeologist.

c. The borehole drilling should be done with a competent drilling rig specifically built for the sedimentary terrain in order to attain this recommended Total Drilled Depth (TDD).

d. The borehole completion should be done using PVC casing material of adequate thickness and not exceeding 6 inches. This will ensure regular production of clean water with better borehole stability.

e. Proper water analysis should be done in a credible and registered analytical laboratory to determine the quality of the water so produced from this borehole.

f. VES 1 is therefore recommended for drilling a productive borehole.

\section{REFERENCES}

[1] Telford, W.M., Geldart, L.P., Sheriff, R. E., Keys, D.A. "Applied Geophysics" Cambridge University Press, London. http://library.wur.nl/WebQuery Lisric/24489 (2012).

[2] http://www.airbornegeophysics.com

[3] Koefoed, 0. "Geosounding Principles", Elsevier pulb. Co., Amsterdam (2000).

[4] Zohdy, A. "A new method for the interpretation of Schlumberger and Wenner Sounding Curves", Geophysics v 54 N 2 pp 245-253 (2013).

[5] Milsom - Wiley, J. "Resistivity methods; nomenclature in Electrical Geophysics" https://onlinelibrary.wiley.com (2011).

[6] "Resistivity methods in Environmental

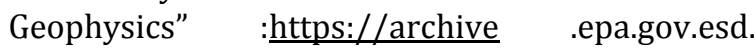
web.html (2016).

[7] “Geodesy for the Electrical Geophysics" Defense Mapping Agency Building 56 US Naval Observatory DMA TR 80-003 Washington D.C 20305, Chapter VII (1984) pp 34-35.

[8] Geoffrey Blewitt. Basics of the GPS Technique, Department of Geomatics, University of
Newcastle, Newcastle upon Tyne, NE1 7RU, United Kingdom (1997).

[9] Georgiadou, P.Y., Knippers, R.A., Kraak, M.J., Sun, Y., Weir, M.J.C. and van Westen, Principles of Geographic Information systems (Chapter 4.2 on spatial referencing), 2nd edition, ITC Educational Textbook, ITC, Enschede, 2001.

[10] Knippers, R.A and Hendrikse J. Coordinate transformations. Kartografisch Tijdschrift, KernKatern 2000-3, (2001).

[11] Pete Bettinger and Krita Merry. Static Horizontal Positions Determined With a Consumer-Grade GNSS Receiver: One Assessment of the Number of Fixes Necessary. Croat. J for. Eng. 33(2012)1.

[12] Standard for New Zealand Geodetic Datum, equations used for datum transformations online resource retrieved on $10^{\text {th }}$ November 2017.

[13] Donald C.T. Choi, James Y. K. Wong and Ben S.B. Chan. "Investigation on GPS Heighting Accuracy with the use of Hong Kong Satellite Positioning Reference Station Network (SatRef) Strategic Integration of Surveying Services" FIG Working Week 2007 Hong Kong SAR, China, 13-17 May (2007).

[14] Ehigiator - Irughe, and O.M. Ehigiator (2011) "3D Modelling of Quarry Site using GPS Observations" Journal of Emerging Trends in Engineering and Applied Sciences 2 (3): pp. 419-428

[15] Ehiorobo, J. O. and Ehigiator - Irughe, R. "Evaluation of Absolute Displacement of Geodetic Control for Dam Deformation Monitoring Using CSRS-PPP Model", Journal of Earth Science and Engineering vol. 2, (2012), pp.277 - 286.

[16] M. O. Ehigiator and R. Ehigiator - Irughe, (2018). "Formulation and Implementation of Mathematical Models Suitable for Deformation Analysis of Structures", Nigerian Journal of Technology, vol. 37, no.2, (2018), pp. $294-301$.

[17] Ehigiator M. 0.1, Oladosu S. O. and EhigiatorIrughe, R. (2017). "Densification of (GNSS) Control Points for Cadastral and Mapping Purposes", Nigerian Journal of Environmental Sciences and Technology, Vol. 1, no.2, (2017), pp. 85 - 96. 